\title{
The Psychological Reality of the Paragraph ${ }^{1}$
}

\author{
Frank Koen, Alton Becker, AND Richard Young \\ The University of Michigan, Ann Arbor, Michigan 48108
}

\begin{abstract}
Three experiments were carried out (a) to assess the degree of agreement with which $\mathrm{Ss}$ identify paragraph boundaries in unindented prose passages, (b) to determine whether a significant proportion of the cues to paragraph structure are formal in nature, (c) to ascertain whether the identification of paragraphs in different kinds of prose differentially depends on semantic, as distinct from formal, cues, and (d) to study developmental changes in paragraphing ability. Nouns, verbs, adjectives and adverbs in 10 English prose passages were replaced by nonsense paralogs and $S$ s identified paragraph boundaries in both English and nonsense versions. The median reliability for paragraphing English passages was .86; for nonsense, .75 . The median correlation between paragraphing of English and nonsense versions of the same passage was .71 . Children approach adult levels of paragraphing more quickly with nonsense passages than with English.
\end{abstract}

Several recent experiments have dealt with the structure of sentences (e.g., Fodor and Bever, 1965; Johnson, 1965; Mehler and Carey, 1967). The problems of paragraph structure, however, have not been studied by psychologists. This paper is an attempt to open up this area. It seems apparent that in ordinary linguistic communication response is to larger meaningful units than the sentence. The paragraph may be one of these units. If so, it may represent a conventional (learned) way of chunking large amounts of information, and $S$ s should then agree in identifying its boundaries. Furthermore, if a grasp of the underlying structure of the sentence contributes to its understanding, perhaps the perception of a paragraph's structure performs a similar service. At this point there is a divergence in thinking about sentence structure and paragraph organization. Sentences are seen as possessing formal characteristics that are independent of meaning while paragraphs are sometimes viewed as arbitrary semantic units. However, there seems to be no a priori reason why the sentence boundary should mark a shift from formal cues to semantic connections. It is

1 This research was supported in part by a contract with the U.S. Office of Education. proposed to change the content words in a prose passage to nonsense paralogs, and have Ss mark paragraph boundaries in both English and nonsense versions; the correlation between the number of paragraph markers placed at the common sentence junctures in the two versions should provide a gross indication of the role of semantic cues.

Perhaps paragraph structures of different kinds of literary prose (i.e., exposition, narration, description, dialogue, etc.) differ in clarity and discriminability as well as in their dependence on formal, as distinct from semantic cues. Therefore, an investigation of paragraph structure should sample each of the commonly accepted literary modes.

Finally, a study of developmental changes in the ability to identify paragraph structures should indicate the degree to which discrimination of formal and semantic cues grows in parallel fashion during successive stages of linguistic development. It is possible that the less extensive and less well-organized vocabulary of children may result in less sensitivity to semantic cues than that exhibited by adults. Perhaps children learn paragraph structure inductively (i.e., without formal tuition) as they appear to learn sentence structure. To what extent, then, can children who can read, 
but who have received no formal instruction in paragraphing identify paragraph boundaries?

\section{METHOD}

Three experiments were conducted. Features common to them all are reported first, followed by mention of the conditions unique to each.

Materials. A total of 11 passages of English prose served as the original set of stimuli. The number of sentences per passage ranged from 15 to 52 ; the number of words, from 216 to 592 . Each passage was printed on a single page with brackets [ ] placed between sentences and at the beginning and end of the passage. Passages 1-10 were also converted to nonsense by replacing all nouns, verbs, adjectives, and adverbs with nonsense paralogs of equal average syllabic length. For example, the sentence "Sloths have no right to be living on the earth today; they would be fitting inhabitants of Mars, where a year is over six-hundred-days long" becomes "Smars have no mirt to be lewling on the kust reteb; they would be tibbing nonentants of Ness, where a reet is over nus cantron tels dan." Word-endings that play a grammatical role (e.g., -ed, -ly, -s, -ing) were retained, as were all sentence punctuation marks, including commas, semicolons, periods and quotation marks. All paragraph indentions were removed. In the nonsense version, a given paralog replaced one and only one English word, and was repeated at every occurrence of the latter. According to the classification system suggested by Rockas (1964), Passages 1 through 4 are examples of exposition; 5 is description; 6 , narration; 7 , drama; 8 , reverie; 9 , dialogue; 10 , persuasion; and 11 , narration. ${ }^{2}$ Seven of the 11 passages did not begin or end with paragraph boundaries, as they were originally written.

Procedure. Each $S$ responded to one English and one nonsense passage; no $S$ responded to the same passage in both English and nonsense versions. One-half paragraphed a nonsense passage first; one-half, an English passage first. Passages were randomly assigned to $S \mathrm{~s}$; the number of $S \mathrm{~s}$ responding to each passage ranged from 9 to 32. Data were collected in group sessions; the number of $S$ s in each session ranged from 6 to 25 .

Each experimental session was conducted as a sequence of tasks with each $S$ working at his own pace, and with successive tasks given him only upon completion of the preceding one. The $S \mathrm{~s}$ were told that the purpose of the experiment was to find out how and why

${ }^{2}$ For detailed paper, extended version, or supplementary material, order NAPS Document NAPS00222 from ASIS National Auxiliary Publications Service, c/o CCM Information Sciences, Inc., 22 West 34th Street, New York, New York 10001; remitting $\$ 1.00$ for microfiche or $\$ 3.00$ for photocopies. we use paragraphs. They were asked to read the passage carefully and to place paragraph markers at the places that seemed right to them without regard to where the author may have put them. It was pointed out that each passage might or might not begin and end with a paragraph.

\section{Experiments 1 and 2}

English $(\mathrm{E})$ and nonsense $(\mathrm{N})$ versions of Passages 1-10 were paragraphed by 9-14 college undergraduates, of whom approximately $50 \%$ were male. Passage $11 \mathrm{E}$ was paragraphed by $32 \mathrm{Ss}$.

\section{Experiment 3}

Subjects. The Ss were elementary, junior-high, and high-school students; data were collected in their classrooms. There were three groups, consisting of $12 \mathrm{Ss} 7$ to 8 years old, $10 S$ s from 10 to 12 years, and $13 S$ s from 14 to 16 years. The sexes were approximately equally balanced within each age group.

Materials. A shortened version of Passage $2 \mathrm{~N}$ and a simple narrative passage taken from a popular magazine (Passage 11E) were used as stimuli.

Procedure. All $S$ s responded to both passages.

\section{RESULTS AND DisCUSSION}

Chi-square was used to compare the distributions of paragraph markers, and of the total number of markers associated with the two orders of presentation (English-nonsense versus nonsense-English) in Exp. 1; there were no significant differences. This variable was therefore ignored in subsequent analyses.

\section{Experiments 1 and 2}

Inter-judge consistency in marking paragraphs in both experiments was quite high. Table 1 presents the combined results for both $\mathrm{E}$ and $\mathrm{N}$ passages. The $S \mathrm{~s}^{\prime}$ paragraphing is not compared with the author's, but is reported only in terms of interjudge reliability. For example, 14 of the 19 sentence junctures in passage $5 \mathrm{E}$ were seen as constituting paragraph boundaries by $20 \%$ or fewer of the $S \mathrm{~s}$, while three of the 19 were thought to mark paragraph boundaries by more than $80 \%$. In other words, there was $80 \%$ or better paragraphing agreement for 17 of the 19 sentence junctures.

Kuder-Richardson Formula 20 (Guilford, 1954) was used to measure interjudge agreement for each passage (see Table 1). The formula is used here to express the consistency 
TABLE 1

Interuduge Consistency in Paragraphing in Exps. 1 and 2

\begin{tabular}{|c|c|c|c|c|c|c|c|}
\hline \multirow[b]{2}{*}{ Passage } & \multirow{2}{*}{$\begin{array}{c}\text { No. } \\
\text { junctures }\end{array}$} & \multicolumn{6}{|c|}{ Percentage of $S$ s marking paragraph } \\
\hline & & $0-20$ & $21-40$ & $41-60$ & $61-80$ & $81-100$ & $\begin{array}{c}\text { (K-R 20) } \\
r_{t t}\end{array}$ \\
\hline $1 \mathrm{E}$ & 14 & $9^{a}$ & 0 & 2 & 2 & 1 & .86 \\
\hline $1 \mathrm{~N}$ & 14 & 8 & 1 & 5 & 0 & 0 & .69 \\
\hline $2 \mathrm{E}$ & 32 & 27 & 1 & 0 & 1 & 3 & .98 \\
\hline $2 \mathrm{~N}$ & 32 & 19 & 7 & 5 & 1 & 0 & .73 \\
\hline $3 \mathrm{E}$ & 22 & 14 & 1 & 4 & 2 & 1 & .86 \\
\hline $3 \mathrm{~N}$ & 22 & 15 & 2 & 4 & 1 & 0 & .87 \\
\hline $4 E$ & 17 & 10 & 3 & 2 & 2 & 0 & .80 \\
\hline $4 \mathrm{~N}$ & 17 & 11 & 0 & 5 & 1 & 0 & .79 \\
\hline $5 \mathrm{E}$ & 19 & 14 & 1 & 1 & $\mathbf{0}$ & 3 & .96 \\
\hline $5 \mathrm{~N}$ & 19 & 10 & 6 & 2 & 1 & 0 & .73 \\
\hline $6 \mathrm{E}$ & 25 & 20 & 2 & 1 & 1 & 1 & .86 \\
\hline $6 \mathrm{~N}$ & 25 & 18 & 1 & 5 & 0 & 1 & .76 \\
\hline $7 \mathrm{E}$ & 53 & 27 & 2 & 2 & 5 & 17 & .95 \\
\hline $7 \mathrm{~N}$ & 53 & 28 & 2 & 2 & 10 & 11 & .92 \\
\hline $8 \mathrm{E}$ & 22 & 10 & 3 & 2 & 7 & 0 & .79 \\
\hline $8 \mathrm{~N}$ & 22 & 11 & 3 & 6 & 1 & 1 & .74 \\
\hline $9 \mathrm{E}$ & 52 & 22 & 3 & 4 & 9 & 14 & .91 \\
\hline $9 \mathrm{~N}$ & 52 & 12 & 11 & 9 & 7 & 13 & .89 \\
\hline $10 \mathrm{E}$ & 25 & 18 & 4 & 2 & 1 & 0 & .75 \\
\hline $10 \mathrm{~N}$ & 25 & 17 & 5 & 3 & 0 & 0 & .53 \\
\hline $11 \mathrm{E}$ & 14 & 8 & 4 & 0 & 1 & 1 & .94 \\
\hline
\end{tabular}

${ }^{a}$ Figure in each cell represents the number of sentence junctures in the passage at which a given percentagerange (e.g., 0-20, 21-40) of Ss' marked paragraphs.

among $S$ s rather than among items (i.e., sentence junctures). It may be interpreted as an index of the ambiguity of the "paragraphing signals" occurring in the passages.

In every case but one (Passage 3 ) interjudge agreement, in terms of K-R 20, is greater for English than for nonsense versions of the same passage, the differential ranging from -.01 to .25 , with a median of .075 . This result may be taken to indicate the degree to which identification of paragraph structures depended on the meanings of the content words in the passage.

Even in the nonsense passages, however, reliability ranges from .53 to .92 ; with a median of .75. These findings indicate that the paragraph is a psychologically real unit. The inference that paragraphing signals are not entirely semantic is supported by Pearson product-moment correlations between $\mathrm{E}$ and
$\mathrm{N}$ versions of the same passage; they range from .42 to .95 , with a median of .71 . These figures represent the correspondence between the proportions of $S$ s placing paragraph markers at common sentence junctures in the two versions.

Further analysis of the relative reliabilities of paragraphing corresponding $\mathrm{E}$ and $\mathrm{N}$ passages yields information on the relations between semantic and formal cues in controlling $S$ s' paragraphing behavior in the various passages. For example, the K-R 20 reliabilities of $E$ Passages 1, 2, 3, 5, 6, 7, and 9 all equal or exceed the median value of .86 . The reliabilities of the $\mathrm{N}$ versions of Passages $1,2,5$, and 6 , however, are decidedly less than those of their corresponding $\mathrm{E}$ passages, the decrement ranging from .10 to .25 . The high reliability of paragraphing in these $E$ passages appears to be based largely on semantic cues. On the other 
hand, there is virtually no decrease in reliability of paragraphing the $\mathrm{N}$ versions of Passages 3 , 7 , and 9 (see Table 1). This suggests that nonsensizing content words in these passages had relatively little effect on paragraphing decisions and that the dominant cues are formal in nature.

Similarly, the K-R 20 reliabilities of $\mathrm{E}$ Passages 5, 8, and 10 are quite low $(.80, .79$, and .75 , respectively). Further investigation shows that the reliability of Passage $10 \mathrm{~N}$ is .22 less than that of $10 \mathrm{E}$. Here, $S$ s apparently based their decisions on salient but ambiguous semantic cues. On the other hand, there is very little decrement in paragraphing reliability of $\mathrm{N}$ Passages 4 and 8 , compared to their $\mathrm{E}$ versions. The inference is that semantic organization in these passages is weak indeed, and that $S$ s responded most readily to formal cues that were themselves ambiguous.

It may be concluded that both semantic and formal markers contribute to the perception of paragraph structures, but that the relationship between the two classes of cues is not a simple one, nor is the constituency of either class. Furthermore, it would appear from these reliabilities and $\mathrm{E}-\mathrm{N}$ correlations that almost any pattern of relationship between the two classes of cues may occur in any of the tested modes.

\section{Experiment 3}

This experiment was designed to study the course of the development of the discriminations required to identify paragraph structures. It can be seen in Table 2 that there is a regular increase in interjudge consistency as a function of increasing age and educational experience, the single reversal being between age groups 10-12 and 14-16 on Passage 2Ns. The youngest age group placed $33 \%$ (Passage $2 \mathrm{Ns}$ ) and $43 \%$ (Passage 11E) of their paragraph markers

TABLE 2

Developmental Changes in Interjudge Consistency in Paragraphing

\begin{tabular}{|c|c|c|c|c|c|c|c|c|}
\hline \multirow[b]{2}{*}{$\begin{array}{l}\text { Passage and } \\
\text { no. junctures }\end{array}$} & \multirow[b]{2}{*}{$\begin{array}{l}\text { Age } \\
\text { level }\end{array}$} & \multicolumn{6}{|c|}{ Percentage of $S$ s marking paragraph } & \multirow[b]{2}{*}{$\begin{array}{l}\text { Correlation } \\
\text { with adults }\end{array}$} \\
\hline & & $0-20$ & $21-40$ & $41-60$ & $61-80$ & $81-100$ & $\begin{array}{c}(\mathrm{K}-\mathrm{R} 20) \\
r_{t}\end{array}$ & \\
\hline \multirow[t]{4}{*}{$\begin{array}{l}2 \mathrm{NS} \\
(28 \text { junctures) }\end{array}$} & $\begin{array}{c}7-8^{a} \\
(n=12)\end{array}$ & $11^{c}$ & 12 & 5 & 0 & 0 & .29 & .10 \\
\hline & $\begin{array}{c}10-12 \\
(n=10)\end{array}$ & 17 & 8 & 2 & 1 & 0 & .69 & .54 \\
\hline & $\begin{array}{c}14-16 \\
(n=12)\end{array}$ & 19 & 7 & 2 & 0 & 0 & .59 & .81 \\
\hline & $\begin{array}{c}\text { Adult } \\
(n=11)\end{array}$ & 21 & 2 & 4 & 1 & 0 & .83 & \\
\hline \multirow[t]{4}{*}{$\begin{array}{l}11 \mathrm{E} \\
\quad(14 \text { junctures })\end{array}$} & $\begin{array}{c}7-8^{b} \\
(n=12)\end{array}$ & 2 & 9 & 2 & 1 & 0 & .41 & -.42 \\
\hline & $\begin{array}{c}10-12 \\
(n=10)\end{array}$ & 5 & 8 & 1 & 0 & 0 & .55 & .32 \\
\hline & $\begin{array}{c}14-16 \\
(n=12)\end{array}$ & 9 & 1 & 2 & 0 & 2 & .92 & .85 \\
\hline & $\begin{array}{c}\text { Adult } \\
(n=32)\end{array}$ & 8 & 4 & 0 & 1 & 1 & .94 & \\
\hline
\end{tabular}

a $33 \%$ of all paragraph markers were placed within sentences.

${ }^{b} 43 \%$ of all paragraph markers were placed within sentences.

${ }^{c}$ Figure in each cell represents the number of sentence junctures in the passage at which a given percentage range (e.g., $0-20,21-40)$ of subjects marked paragraphs.

${ }^{d}$ Corrected for attenuation. 
within sentences, indicating that the concept "paragraph" was not meaningful to them. Inquiry at the school they attended elicited the information that their first formal tuition in paragraphing occurs in the third grade-the grade in which these children were enrolled. The degree to which the identification of paragraph structures is dependent on direct teaching, as distinct from the inductive learning that may accompany increased reading skills, cannot be determined from these data, since the two are completely confounded.

The correlations in the placing of paragraph markers between these children and college students may be seen in Table 2 . It may be noteworthy that the correlations are greater for the nonsense than for the English passage in the two younger groups. These data are compatible with the idea that the development of the syntactic system is more rapid than that of the semantic. Improvement in the processing of formal cues appears to consist of increasingly finer discriminations of the cues used by adults. In the semantic realm, it may be a different story. A fairly massive realignment of the system of semantic cues to which children respond must take place for the corrected correlations between children's and adults' paragraphing to change from -.42 to .85 for Passage 11E.
In the light of the interjudge reliabilities, it seems clear that the paragraph is a psychological unit. That this unit often depends for its identification to a significant extent on formal as well as semantic cues is strongly suggested by a median correlation of .71 between the proportion of $S$ s marking paragraphs in corresponding $\mathrm{E}$ and $\mathrm{N}$ passages. Furthermore, it has been shown that it is possible to infer for each passage the relative saliency of the classes of semantic and formal cues, as well as the ambiguity of each class. Future investigations will be devoted to finer delineations of the constituency and operating characteristics of each class, with an eye toward developing an overall model of paragraph structure.

\section{REFERENCES}

Fodor, J. A., AND Bever, T. G. The psychological reality of linguistic segments. J. vexb. Learn. verb. Behav., 1965, 4, 414-420.

GUILFORD, J. P. Psychometric methods. New York: McGraw-Hill, 1954.

JoHnson, N. F. The psychological reality of phrasestructure rules. J. verb. Learn. verb. Behav., 1965, 4, 469-475.

Mehler, J., AND CAREy, P. Role of surface and base structure in the perception of sentences. $J$. verb. Learn. verb. Behav., 1967, 6, 335-338.

Rockas, L. Modes of rhetoric. New York: St. Martin's Press, 1964.

(Received May 8, 1968) 